\title{
Postural instability in Parkinson's patients
}

\author{
Amir Hassan Habibi, ${ }^{1}$ Sogand Arab, ${ }^{1}$ Farzad Sina, ${ }^{1}$ Saeed Razmeh ${ }^{2}$ \\ ${ }^{1}$ Iran University of Medical Sciences, Tehran; ${ }^{2}$ Yasuj University of Medical Sciences, Yasuj, Iran
}

\begin{abstract}
Postural instability is a major cause of disability in patients with Parkinson's disease and therefore increases their dependence on other people and decreases the quality of life in these patients. This study aimed to determine the prevalence of Postural instability and its onset in patients with Parkinson's disease. We evaluated 250 Parkinson's patients who referred to the movement disorder Clinic during 2016. All patient information, including gender, age, onset time of symptoms, as well as the time interval between symptoms start to postural instability were recorded. A total of 41 patients $(16.4 \%)$ had a Postural instability, there was no significant difference between the two groups with and without instability in the distribution of sex and mean age. The mean age for the onset of symptoms in men and women was $54 \pm 11 / 3$ and $50 / 6 \pm 12.2$ respectively Which was significantly lower in women than in men ( $P$ value: 0.026). Also, the mean time between the onset of symptoms of Parkinson's disease and the onset of motor instability was 5.2 \pm 4.9 . This time was $8.2 \pm 4.5$ in men and $11.5 \pm 5.7$ in women which is significantly shorter in men than women (P value: 0.047 ). In our society, $16.4 \%$ of patients with Parkinson's disease have a motor instability .this outbreak is independent of the variables of gender and age of the patients. According to our study, although women tend to experience signs of Parkinson's disease earlier than men, the time interval between the onset of the disease manifestation and the onset of postural instability in males was shorter than that of women.
\end{abstract}

\footnotetext{
Correspondence: Saeed Razmeh, Yasuj University of Medical Sciences, Yasuj, Iran.

E-mail:srazmeh@yahoo.com

Key words: Postural instability, Parkinson's disease, gait imbalance

Contributions: the authors contributed equally.

Conflict of interest: the authors declare no potential conflict of interest.

Funding: none.

Received for publication: 28 May 2018.

Revision received: 5 June 2018.

Accepted for publication: 9 June 2018.

This work is licensed under a Creative Commons Attribution NonCommercial 4.0 License (CC BY-NC 4.0).

(C) Copyright A.H. Habibi et al., 2018

Licensee PAGEPress, Italy

Annals of African Medical Research 2018; 1:26

doi:10.4081/aamr.2018.26
}

\section{Introduction}

Stability and balance are the basis of correct walking and maintaining the position. In fact, Postural instability involves a disturbance in balance that impair the position of the body in standing and motion. ${ }^{1}$ It is one of the most important features of Parkinson's disease along with other characteristics such as tremor, rigidity and bradykinesia. ${ }^{2}$ The Pathophysiology of Postural instability is very complex, and yet its basic mechanism is not well defined. ${ }^{3}$ It may appears in the early stages of the illness and may be associated with Parkinson plus diseases, such as progressive supranuclear palsy and multiple system atrophy. It usually exacerbated by the progression of the disease. ${ }^{4,5}$ Given that Postural instability causes a lot of disability with the progression of the disease and a decrease in the quality of life of patients, in this study, we determine the prevalence of Postural instability and its onset in patients with Parkinson's disease.

\section{Materials and Methods}

This cross-sectional study was conducted in a neurology clinic of Rasoul-Akram Hospitals affiliated with the Iran University of Medical Sciences and was approved by the Ethics Committee of the College. The study population included 250 patients with Parkinson's disease. The data collections were done through interviews and physical examination in the neurology clinic. All patients signed an informed consent. The diagnosis of Postural instability in the patients was based on the retropulsion test as described in the MDS-UPDRS scale. After making the diagnosis of Postural instability, the Parkinson patients were divided into two groups: those with and without Postural instability. The Clinical characteristics which were assessed in both groups included gender, age, onset time of symptoms, as well as the time interval between symptoms start to postural instability. We used SPSS 22 to analyze data and a p-value less than 0.05 was considered as a significant level. The mean and standard deviation (SD) were used to characterize the study population and the differences between two groups were compared using paired t-tests.

\section{Results}

The 250 patients known case of Parkinson disease were studied, 150 males $(60 \%)$ and 100 females $(40 \%)$. The age range was $35-87$ years. The mean age was $62.8 \pm 10.5$ years. The 41 patients $(16.4 \%), 16$ women $(39 \%)$ and 25 men $(61 \%)$, out of a total of 250 subjects had postural instability and in the patient without postural instability, there were 84 women (59.8\%) and 125 men (40.2 \%) and the mean age in patients with and without postural instability was $63.8 \pm 10.3$ and $62.8 \pm 10.5$ respectively. There was no significant difference between the two groups with and without instability in the distribution of sex and mean age. The mean age for the onset of symptoms in men and women was $54 \pm 11 / 3$ and $50.6 \pm 12.2$ 
years respectively Which was significantly lower in women than in men (P-value: 0.026). Also, the mean age for the onset of postural instability in men and women was $60 \pm 10 / 3$ and $57 / 8 \pm 10.7$ respectively that there was not significant difference between two groups (P-value: 0.541). Also, the mean time between the onset of symptoms of Parkinson's disease and the onset of motor instability was $5.2 \pm 4.9$ years. This time was $8.2 \pm 4.5$ in men and $11.5 \pm 5.7$ in women which is significantly shorter in men than women (P-value: $0.047)$.

\section{Discussion}

The Postural instability is a common disorder in Parkinson's disease that can disable the patients. The patients with postural and gait instability have a lower quality of life and more anxiety than other Parkinson patients. ${ }^{6,7}$ In our study, the prevalence of Postural instability was $16.4 \%$. In study by Błaszczyk et al., that assessed postural instability in patients with Parkinson's disease, shows that the sway in patients associated with increased severity of disease and increased tendency to fall. ${ }^{8}$ In our study, time between the onset of symptoms of Parkinson's disease and the onset of postural instability is significantly shorter in men than women but the onset of symptoms was significantly lower in women than in men. In another study by Adkin et al. shows that Fear of falling and falling in Parkinson's patients is higher than healthy people also the patients with postural instability have more fear of falling. ${ }^{9}$ The Risk of falling, in addition to Postural instability, depends on other factors, such as age, cognitive impairment, freezing gait, poor balance and leg weakness, postural hypotension and drugs. ${ }^{10}$ The postural instability may appears in the early stages of the Parkinson disease usually exacerbated by the progression of the disease. ${ }^{11}$ The results of Sydney multi-centre longitudinal study of Parkinson disease shows that in the 2 years follow-up of the patients, 34\% have postural instability, in the 10 years follow-up $71 \%$ of patients have postural instability and 15 years later, $92 \%$ of patients have postural instability. ${ }^{12-14}$ However, there is some studies that shows, Physical Therapy intervention can improve the postural instability, but this recovery may not be diminished the falling. ${ }^{15}$ The anticholinergic drugs increase the risk of falling in the old age. Levodopa/Carbidopa Intestinal Gel can improve the postural instability and freezing. ${ }^{16,17}$ Also in another study Apo morphine that is prescribed continuous subcutaneous, can improved the gait imbalance. ${ }^{18}$ In meta-analysis study that assess the effects of Pedunculopontine nucleus DBS on Postural instability and gait disorder in patients with Parkinson disease, k.shows PPN DBS may improve the postural instability. ${ }^{19,20}$

\section{Conclusions}

Postural instability has the disabling effect on quality of life of patients with Parkinson disease. Although its precise mechanism is not well-established, its early diagnosis and treatment can help improve their daily activities.

\section{References}

1. Winter DA. Human balance and posture control during stand- ing and walking. Gait Posture 1995;3:193-214.

2. Jankovic J. Parkinson's disease: clinical features and diagnosis. J Neurol Neurosurg Psychiatry 2008;79:368-76.

3. Bosek M, Grzegorzewski B, Kowalczyk A, Lubiński I. Degradation of postural control system as a consequence of Parkinson's disease and ageing. Neurosci Lett 2005;376:21520.

4. Klawans HL, Topel JL. Parkinsonism as a falling sickness. JAMA 1974;230:1555-7.

5. Nardone A, Schieppati M. Balance in Parkinson's disease under static and dynamic conditions. Movement Disord 2006;21:1515-20.

6. Dissanayaka NNW, Sellbach A, Matheson S, et al. Anxiety disorders in Parkinson's disease: Prevalence and risk factors. Movement Disord 2010;25:838-45.

7. Hariz GM, Forsgren L. Activities of daily living and quality of life in persons with newly diagnosed Parkinson's disease according to subtype of disease, and in comparison to healthy controls. Acta Neurol Scand 2011;123:20-7.

8. Błaszczyk JW, Orawiec R. Assessment of postural control in patients with Parkinson's disease: Sway ratio analysis. Hum Movem Sci 2011;30:396-404.

9. Adkin AL, Frank JS, Jog MS. Fear of falling and postural control in Parkinson's disease. Movement Disord 2003;18:496502.

10. Latt MD, Lord SR, Morris JGL, Fung VSC. Clinical and physiological assessments for elucidating falls risk in Parkinson's disease. Movement Disord 2009;24:1280-9.

11. Bloem B. Postural instability in Parkinson's disease. Clin Neurol Neurosurg 1992;94:41-5.

12. Hely MA, Morris JG, Rail D, et al. The Sydney Multicentre Study of Parkinson's disease: a report on the first 3 years. J Neurol Neurosurg Psychiatry 1989;52:324-8.

13. Hely MA, Morris JGL, Reid WGJ, Trafficante R. Sydney multicenter study of Parkinson's disease: Non-L-dopa-responsive problems dominate at 15 years. Movement Disord 2005;20:190-9.

14. Hely MA, Morris JGL, Traficante R, et al. The Sydney multicentre study of Parkinson's disease: progression and mortality at 10 years. J Neurol Neurosurg Psychiatry 1999;67:300-7.

15. Dibble LE, Addison O, Papa E. The effects of exercise on balance in persons with Parkinson's disease: a systematic review across the disability spectrum. J Neurol Phys Ther 2009;33:1426.

16. Chung KA, Lobb BM, Nutt JG, Horak FB. Effects of a central cholinesterase inhibitor on reducing falls in Parkinson disease. Neurology 2010;75:1263-9.

17. Devos D. Patient profile, indications, efficacy and safety of duodenal levodopa infusion in advanced Parkinson's disease. Movement Disord 2009;24:993-1000.

18. Hughes A, Bishop S, Kleedorfer B, et al. Subcutaneous apomorphine in Parkinson's disease: response to chronic administration for up to five years. Movement Disord 1993;8:165-70.

19. Plaha P, Gill SS. Bilateral deep brain stimulation of the pedunculopontine nucleus for Parkinson's disease. Neuroreport 2005; $16: 1883-7$.

20. Stefani A, Lozano AM, Peppe A, et al. Bilateral deep brain stimulation of the pedunculopontine and subthalamic nuclei in severe Parkinson's disease. Brain 2007;130:1596-607. 